\title{
Muscle Architecture In Patients With Sjogren's Syndrome
}

\author{
Duygu Tecer ${ }^{1}$, Dilek Büyükşireci ${ }^{2}$, ZAFER GÜNENDİ ${ }^{3}$, Jale Meray ${ }^{4}$, and Feride Gogus ${ }^{4}$ \\ ${ }^{1}$ Ankara Gulhane Egitim ve Arastirma Hastanesi \\ ${ }^{2}$ Hitit University Faculty of Medicine \\ ${ }^{3}$ Gazi University Faculty of Medicine \\ ${ }^{4}$ Gazi Universitesi Tip Fakultesi
}

December 28, 2020

\begin{abstract}
Aim: To investigate the effect of primary (pSS) on skeletal muscle architecture and strength. Method: 19 pSS patients and 19 age, body mass index and sex matched healthy controls were included. Symptoms of subject's were assessed with ESSPRI (The EULAR Sjogren's Syndrome Patient Reported Index), anxiety and depression with the Hospital Anxiety and Depression Scale (HADS), fatigue with Multidimensional Assessment of Fatigue scale (MAF), functionality with HAQ. Ultrasonographic evaluations were performed with a multifrequency linear probe from quadriceps femoralis, gastrocnemius and soleus of the bilateral lower extremity. Muscle thickness, pennation angle and fascicle length were measured. Isokinetic knee muscle strength tests were performed at 60 and $180^{\circ} / \mathrm{s}$. Isokinetic ankle muscle strenght tests were performed at 30 and $120^{\circ} / \mathrm{s}$. Result: In pSS group, mean ESSPRI was 7.70 \pm 1.17 . Scores of depression ( $10.05 \pm 3.09$ vs $4.47 \pm 2.29 \mathrm{p}<0.0001)$, anxiety (8.26 \pm 4.28 vs $3.79 \pm 2.42 \mathrm{p}<0.0001)$, functionality $(0.94 \pm 0.78$ vs $0.22 \pm 0.26, \mathrm{p}<0.0001)$, fatigue $(37.69 \pm 5.47$ vs $17.69 \pm 5.26, \mathrm{p}<0.0001)$ were significantly higher in patients with pSS than healthy controls. In dominant leg, pennation angle of vastus medialis was significantly greater in healthy controls than in patients with pSS $(\mathrm{p}=0.049)$. The other ultrasonographic measurements were similar between the two groups. Peak torque/body weight of knee and ankle muscle were found to be similar. Conclusion: Although patients with pSS have some minor structural changes on ultrasonographic evaluation, isokinetic muscle strength were similar between groups. In patients with pSS, disease activity and fatigue level were negatively correlated with isokinetic muscle strength measurement.
\end{abstract}

\section{Hosted file}

MANUSCR \selectlanguage\{polish\} $\dot{I} \backslash$ selectlanguage\{english\}PT+T $\backslash$ selectlanguage $\{$ polish $\} \dot{I} \backslash$ selectlanguage $\{$ engl available at https://authorea.com/users/385799/articles/501027-muscle-architecture-inpatients-with-sjogren-s-syndrome

\section{Hosted file}

table.pdf available at https://authorea.com/users/385799/articles/501027-muscle-architecturein-patients-with-sjogren-s-syndrome 